Prepared for the U.S. Department of Energy

under Contract DE-AC05-76RL01830

\title{
Validating the Melusine Gamma Spectroscopy Tool
}

\section{LE Erikson}

M Keillor

TJ Stavenger

November 2013

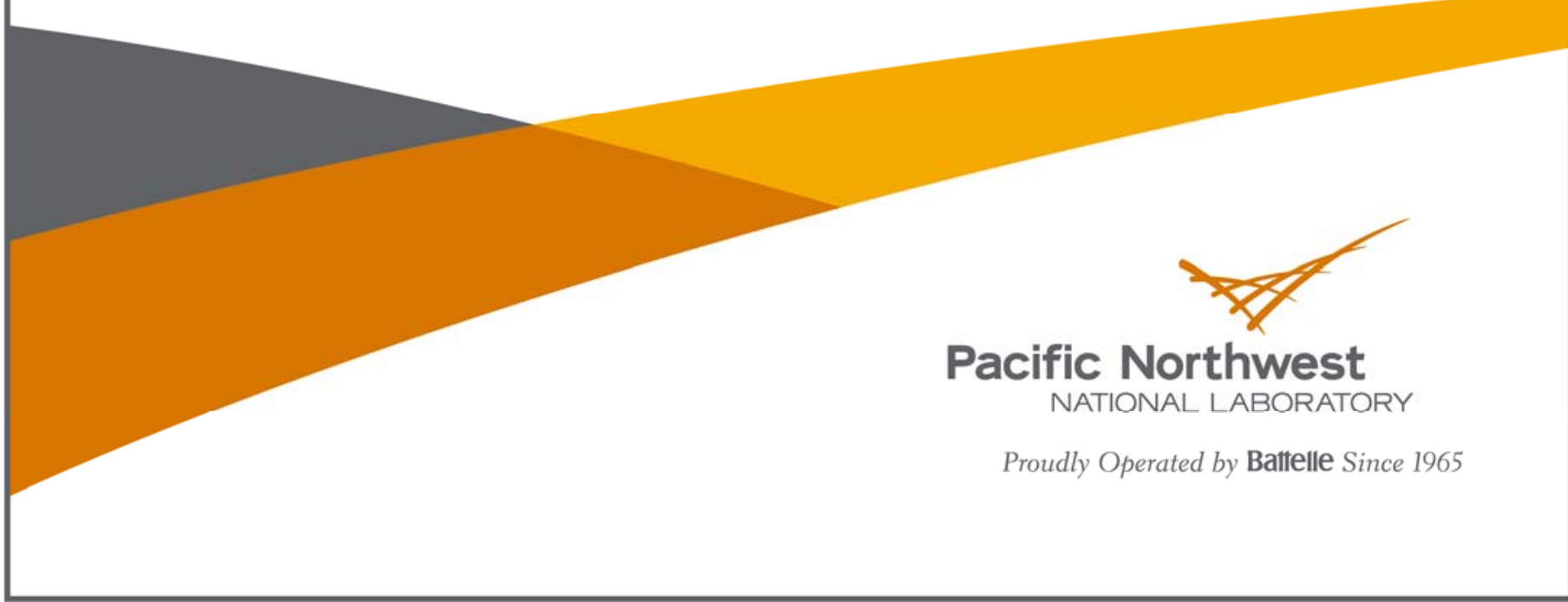




\section{DISCLAIMER}

This report was prepared as an account of work sponsored by an agency of the United States Government. Neither the United States Government nor any agency thereof, nor Battelle Memorial Institute, nor any of their employees, makes any warranty, express or implied, or assumes any legal liability or responsibility for the accuracy, completeness, or usefulness of any information, apparatus, product, or process disclosed, or represents that its use would not infringe privately owned rights. Reference herein to any specific commercial product, process, or service by trade name, trademark, manufacturer, or otherwise does not necessarily constitute or imply its endorsement, recommendation, or favoring by the United States Government or any agency thereof, or Battelle Memorial Institute. The views and opinions of authors expressed herein do not necessarily state or reflect those of the United States Government or any agency thereof.

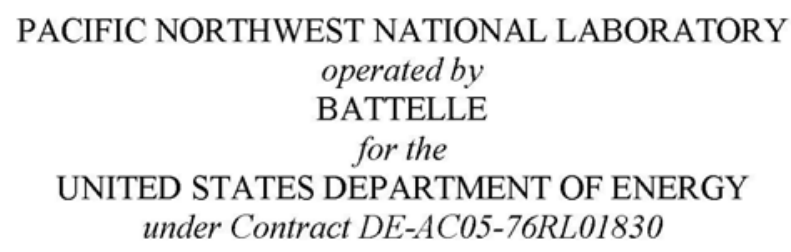

Printed in the United States of America

$$
\begin{aligned}
& \text { Available to DOE and DOE contractors from the } \\
& \text { Office of Scientific and Technical Information, } \\
& \text { P.O. Box 62, Oak Ridge, TN 37831-0062; } \\
& \text { ph: (865) 576-8401 } \\
& \text { fax: (865) 576-5728 } \\
& \text { email: reports@adonis.osti.gov }
\end{aligned}
$$

Available to the public from the National Technical Information Service 5301 Shawnee Rd., Alexandria, VA 22312 ph: (800) 553-NTIS (6847)

email: orders@ntis.gov <http://www.ntis.gov/about/form.aspx>

Online ordering: http://www.ntis.gov 


\section{Validating the Melusine Gamma Spectroscopy Tool}

LE Erikson

M Keillor

TJ Stavenger

November 2013

Prepared for

the U.S. Department of Energy under Contract DE-AC05-76RL01830

Pacific Northwest National Laboratory

Richland, Washington 99352 



\section{Executive Summary}

This technical report describes testing to evaluate the gamma spectroscopy tool, Melusine, under development by Pacific Northwest National Laboratory. The goal was to verify that the software can successfully be used to provide accurate results and statistical uncertainties for the detection of isotopes of interest and their activities. Of special interest were spectra similar to those produced by radionuclide stations that contribute to the Comprehensive Nuclear Test Ban Treaty Organization's International Monitoring System.

Two data sets were used to test Melusine's capabilities. The first was the result of a multi-lab calibration effort based on neutron activations produced at the University of California at Davis. The second was taken from the Proficiency Test Exercises conducted by the CTBTO directly in 2005. In 37 of 42 cases, Melusine produced results in agreement with the best answer presently available, in most cases with calculated uncertainties comparable to or better than competing analyses. In fact, Melusine technically provided one more result than CTBTO's PTE analyses that agreed with the "book answer" (Monte Carlo simulation).

Despite these promising results, the Melusine software is still under development. Effort is especially needed to simplify its analysis process, improve stability, and provide user documentation. Some significant analysis tasks require further vetting, such as those to address summing effects. However, our test results indicate that Melusine's calculations as presently implemented are sound and can be used to reliably analyze spectra from the CTBTO's radionuclide stations. 

PNNL-22992

\section{Acronyms and Abbreviations}

$\operatorname{CTBT}(\mathrm{O})$

Comprehensive Nuclear-Test-Ban Treaty (Organization)

DCAL

(U.C.)Davis Calibration Tests

FY

Fiscal year

IMS

CTBTO’s International Monitoring System

PNNL

Pacific Northwest National Laboratory

PTE

Proficiency Test Exercises

UC Davis

University of California at Davis

VGSL

CTBTO's Virtual Gamma Spectroscopy Laboratory 



\section{Contents}

Executive Summary ……..................................................................................................................................ii

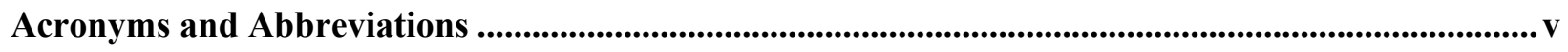

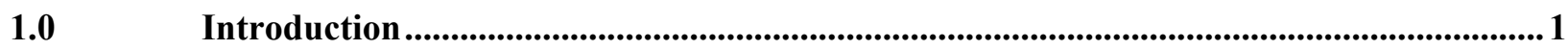

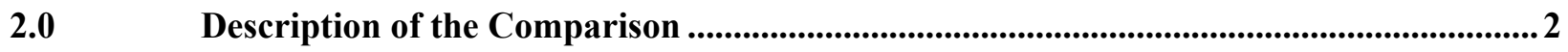

2.1 PNNL's Participation in the Davis Calibration Exercises ................................................2

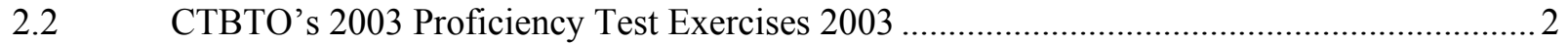

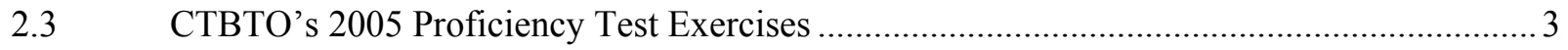

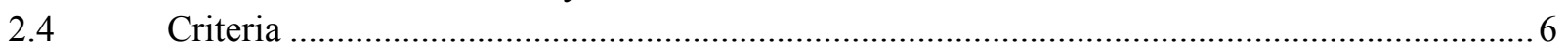

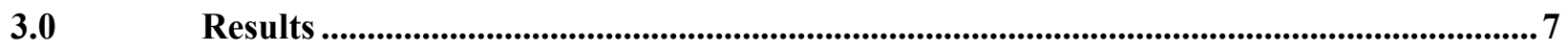

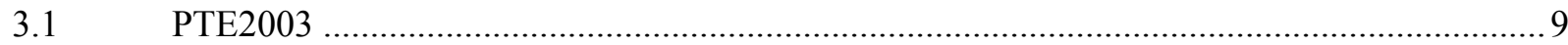

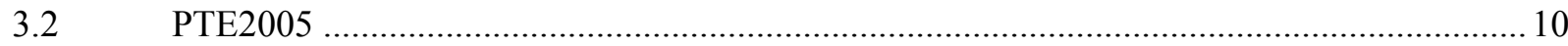

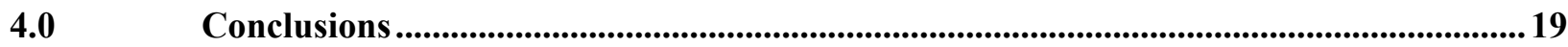

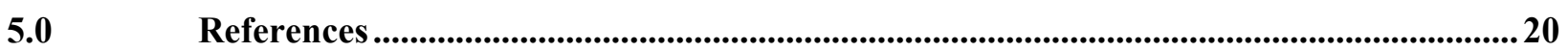




\section{Figures}

Figure 1: Sample 1: Simulating a blank filter paper with $57.9 \mathrm{~Bq}$ of ${ }^{7} \mathrm{Be}$ and $10.0 \mathrm{~Bq}$ of ${ }^{210} \mathrm{~Pb}$ injected into the spectrum. Sample 2 differed only by the amount of injected activities for the same isotopes.

Figure 2: Sample 3 simulates a limited list (including ${ }^{140} \mathrm{La},{ }^{140} \mathrm{Ba},{ }^{132} \mathrm{Te},{ }^{132} \mathrm{I}$ ) of fission products at the low activity of $10-20 \mathrm{mBq}$ each

Figure 3: Sample 4 simulates a combination of fission products $\left({ }^{126} \mathrm{Sb}-,{ }^{131} \mathrm{I},{ }^{137} \mathrm{Cs}\right)$ with activities ranging from 0.015 to $0.13 \mathrm{~Bq}$ .5

Figure 4: Sample 5 represents the most complex spectrum for analysis. In this case the isotopes are a mixture of fission products $\left({ }^{103} \mathrm{Ru},{ }^{106} \mathrm{Ru},{ }^{132} \mathrm{Te},{ }^{132} \mathrm{I},{ }^{137} \mathrm{Cs},{ }^{140} \mathrm{Ba},{ }^{140} \mathrm{La}\right)$ and the ${ }^{239} \mathrm{~Np}$ activation product.

Figure 5: Fitting the 497.1-keV gamma (blue line) in Sample 5 ..............................................12

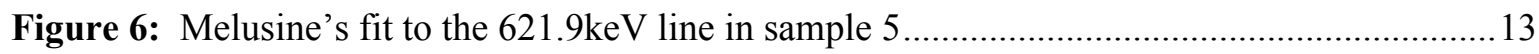

Figure 7: Fitting the weak 228.2-keV peak (blue line) in Sample3 ...........................................14

Figure 8: Fitting the stronger peak (blue line) in Sample 5, which includes interference from

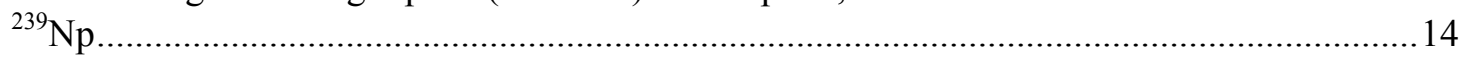

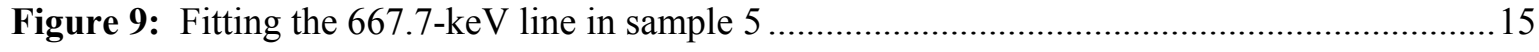

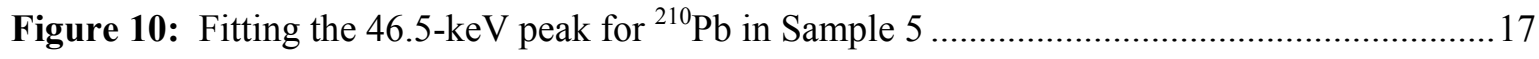

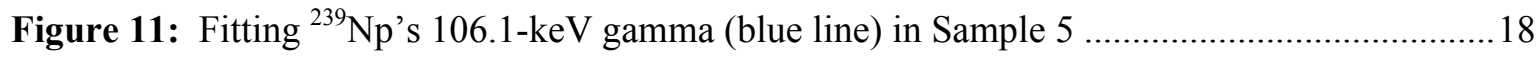

\section{Tables}

Table 1: DCAL30....... 7

Table 2: Summary Table Describing Injected and Measured Activities for Each Sample (all values in Becquerels) 


\subsection{Introduction}

Pacific Northwest National Laboratory (PNNL) is currently conducting a suite of projects to research detection techniques in support of the 1968 Treaty on the Non-Proliferation of Nuclear Weapons. This effort includes the RNLabs project and its follow-on work under the CASCADES project, which completed the construction of a new, high-efficiency germanium crystal array in an ultra-low background environment. To utilize these detectors, PNNL has developed the gamma spectroscopy software "Melusine" to support the efficient analysis of list-mode data from complex detector arrays. Although still under development, Melusine can currently be automated to process large numbers of spectra. Additionally, in many cases, Melusine is capable of reproducing the steps an expert would take in analyzing a spectrum and effectively applying them to similar data sets.

While the IMS system today does not produce list-mode data, there is a need to process the vast amount of spectral data transmitted from the particulate radionuclide stations quickly. For this reason, INSIGHT project efforts in fiscal year (FY) 2013 included tests to validate the analysis results produced by Melusine, which are thus far consistent with current industry-standard analysis tools such as Genie 2000. This report describes the results of those tests. 


\subsection{Description of the Comparison}

This section describes the source and nature of the data used for the Melusine validation. In all cases, the objective was to identify sources of gamma spectra and their accepted characterizations relevant to processing IMS particulate station data.

\subsection{PNNL's Participation in the Davis Calibration Exercises}

University of California at Davis (UC Davis) has been producing neutron activation samples for a series of inter-laboratory gamma spectroscopy calibrations known collectively as Davis Calibration Exercises (DCAL). During the experiments, high-purity metal foils are irradiated with high-energy neutrons produced after a beryllium target is bombarded by protons. This irradiation is performed at the UC Davis cyclotron. Each exercise is identified by an ordinal numeral in the series.

During the DCAL 30 exercise, the samples created for PNNL's CASCADES array were approximately 10 times more radioactive than those measured in past DCAL exercises (Friese et al. 2013). The CASCADES detector is intended to utilize high efficiency and selectivity for low-activity samples, but for these calibration tasks higher radioactivity rates are desired. However, each of these "high-rate" samples for CASCADES still contain significantly lower activity than is typically used for measurements on PNNL's standard laboratory high-purity germanium (HPGe) systems.

Samples were counted at multiple times and for varying durations, starting with a five-minute count to look for strong but short-lived isotopes, and eventually progressing to multiple-hour counts for higher statistics. The four samples were rotated through the system to assure count times and durations were similar for each sample (Friese et al. 2013).

\subsection{CTBTO’s 2003 Proficiency Test Exercises 2003}

PNNL obtained the test data, analysis results, and technical report for CTBTO's 2003 Proficiency Test Exercises for radionuclide laboratories supporting the network of IMS radionuclide stations (PTE2003) (CTBTO 2004). This data included a sample spectrum to evaluate, calibration spectra, and a blank spectrum for background subtraction purposes.

The following text, taken from the PTE2003 Technical Report (op. cit.), describes the purpose, approach and results of this test:

As part of the ongoing proficiency test programme for the radionuclide laboratories supporting the International Monitoring System (IMS) network, the Provisional Technical Secretariat (PTS) organized a proficiency test exercise in 2003 (PTE2003). This time, instead of a spiked reference sample, participants analyzed a gamma spectrum, which was produced by a Monte Carlo simulation based on an analysis of a real measurement. This measurement was made by the Swedish National Defense Research Establishment, in late October 1980, of a sample containing fission debris corresponding to about $3 \times 10^{9}$ fissions in an atmospheric nuclear explosion about two weeks earlier. The simulation was done by the Virtual Gamma Spectroscopy Laboratory (VGSL) code that has been developed in the Radionuclide Development Unit of the 
International Data Centre (IDC) Division of the PTS using a virtual detector system and as a core the well known Monte Carlo transport code MCNP.

To enable analysis at laboratories of the spectrum not measured on their own detectors, a set of supporting data was provided in advance. All spectra were delivered by email. The exercise included a quick response step, with reporting within four hours of receipt of the reference spectrum and a thorough analysis step, where participants were given 20 days to report their final results. All 16 laboratories took part in PTE2003, and returned analysis results generally according to the required time lines.

The radionuclides used in the simulation of the reference spectrum consisted of 24 fission products, 5 activation products, cosmic ray produced ${ }^{7}$ Be and the radon daughter lead212 family of ${ }^{212} \mathrm{~Pb},{ }^{212} \mathrm{Bi}$ and ${ }^{208} \mathrm{Tl}$ (simulated as one entity); in total 31 entities. To that a ${ }^{40} \mathrm{~K}$ signal was added from a selected blank spectrum. The total number of reference nuclides was hence 34, of which at least 32 could be judged to be present from the spectrum. The number of correct identifications in the preliminary analysis reports was 285 , i.e. $56 \%$ out of $512(=16 \times 32)$, and the number was 400 in the final analysis reports, i.e. $78 \%$. The corresponding numbers for agreement of activity results with the reference values were $38 \%$ and $65 \%$ respectively. Five of the preliminary and 10 of the final zero times were in agreement with the reference value (Executive Summary).

\subsection{CTBTO's 2005 Proficiency Test Exercises}

The PTE2003 process was repeated in 2005. This time five samples' spectra with varying degrees of complexity and isotope intensity were simulated by Monte Carlo techniques along with the blank and calibration data. However, instead of a report summarizing the results from 16 participating laboratories (as in PTE2003), PNNL has the documentation of the isotopes and activities used to generate the test spectra and the analysis results from two internal CTBTO analyses. These data allow for a comparison with Melusine analysis results; however, no technical report has been identified to provide further isotope-specific insights.

Despite the limitations on documentation, the PTE2005 data set offers a superior test of analysis capabilities over PTE2003. Having five samples, each containing a different mix of isotopes, offers a more comprehensive picture of the circumstances in which different analysis tools succeed and fail. Additionally, the PTE2005 data set focused on the detection and measurement of activities in the $10-$ $100-\mathrm{mBq}$ range, which is a more challenging exercise than the Becquerel-level activities included in PTE2003. For this reason, the analysis and comparison of the PTE2005 data was emphasized over PTE2003. 
PNNL-22992

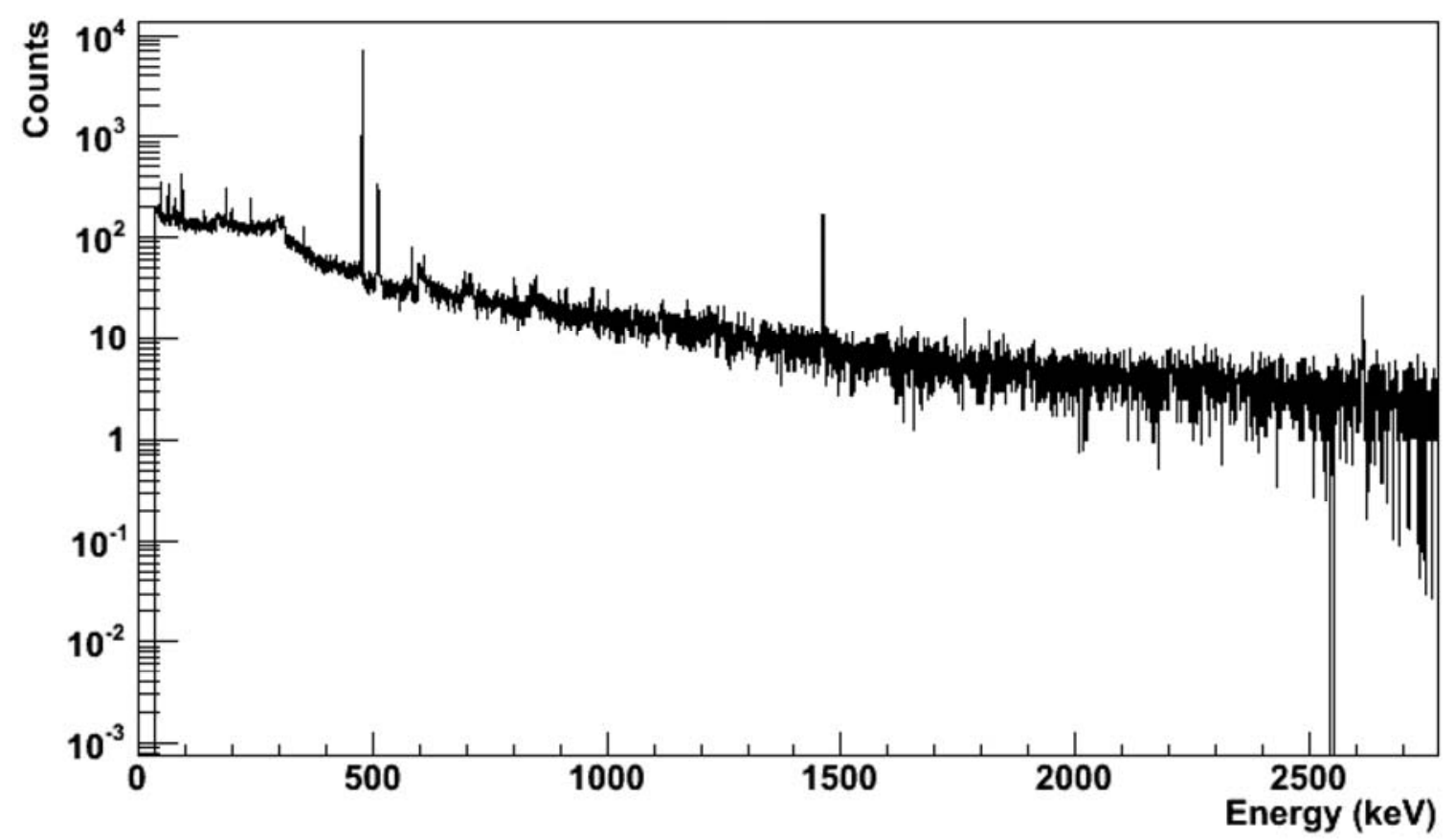

Figure 1: Sample 1: Simulating a blank filter paper with $57.9 \mathrm{~Bq}$ of ${ }^{7} \mathrm{Be}$ and $10.0 \mathrm{~Bq}$ of ${ }^{210} \mathrm{~Pb}$ injected into the spectrum. Sample 2 differed only by the amount of injected activities for the same isotopes.

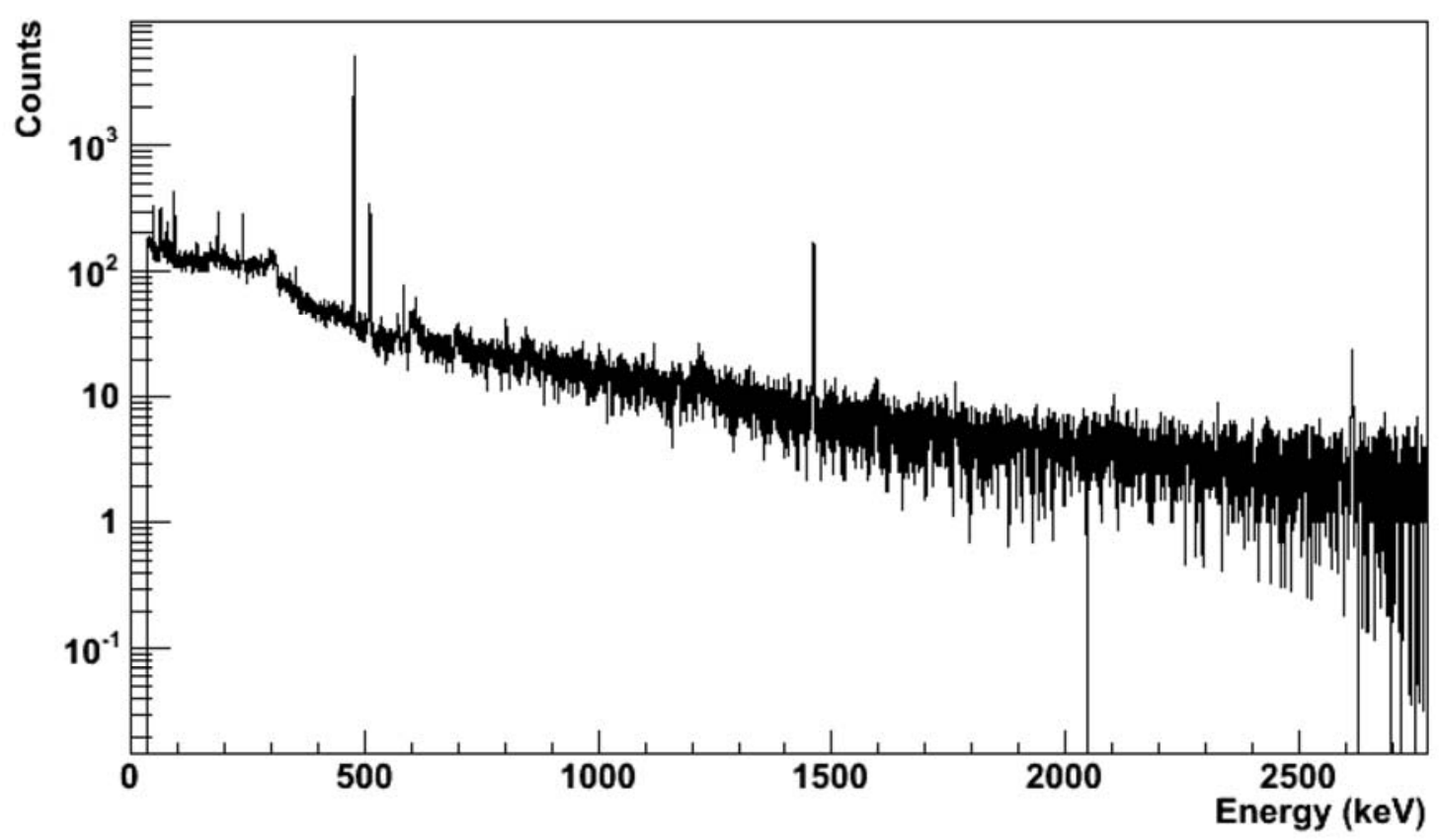

Figure 2: Sample 3 simulates a limited list (including ${ }^{140} \mathrm{La},{ }^{140} \mathrm{Ba},{ }^{132} \mathrm{Te},{ }^{132} \mathrm{I}$ ) of fission products at the low activity of $10-20 \mathrm{mBq}$ each 
PNNL-22992

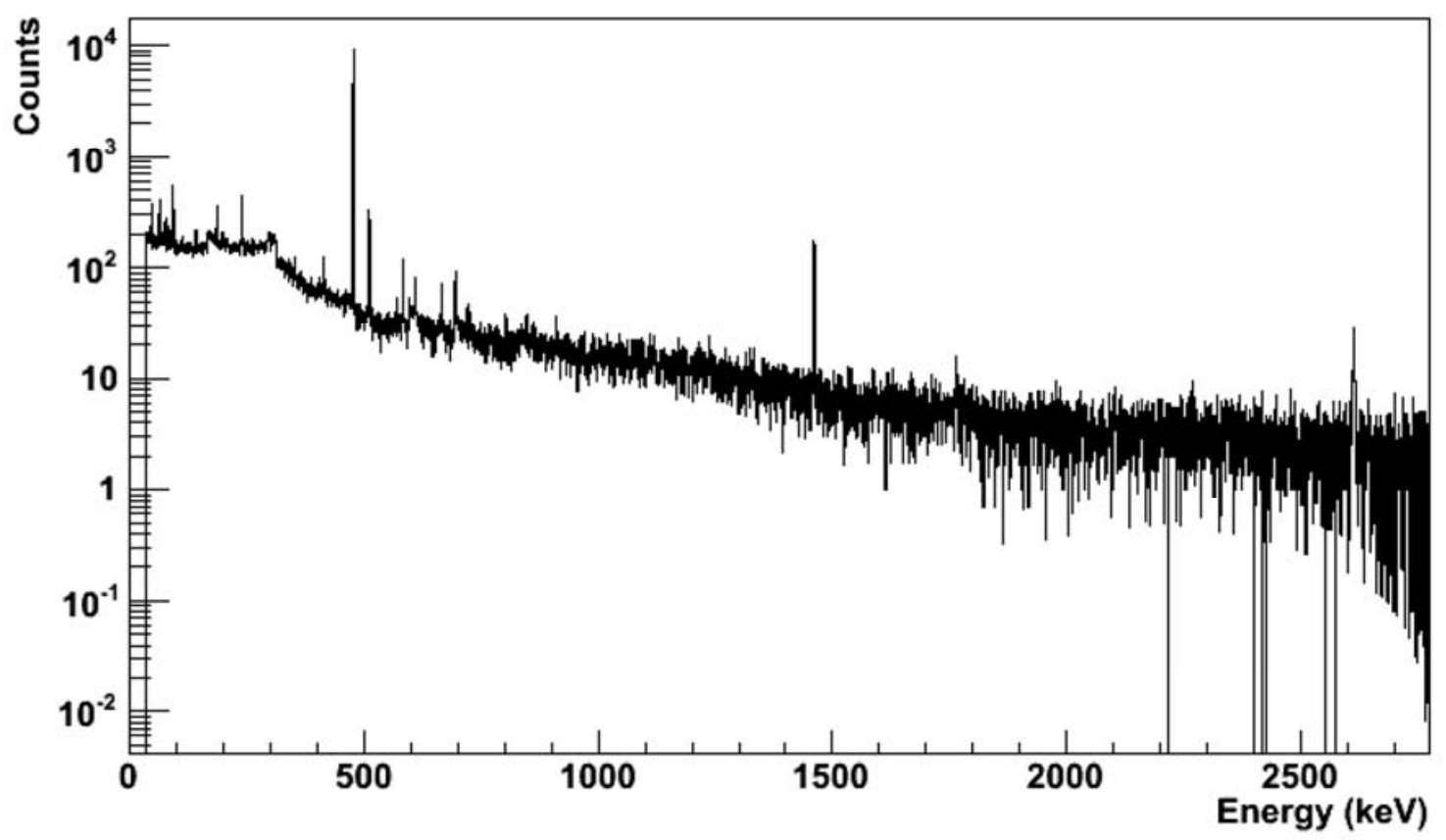

Figure 3: Sample 4 simulates a combination of fission products $\left({ }^{126} \mathrm{Sb}-,{ }^{131} \mathrm{I},{ }^{137} \mathrm{Cs}\right)$ with activities ranging from 0.015 to $0.13 \mathrm{~Bq}$

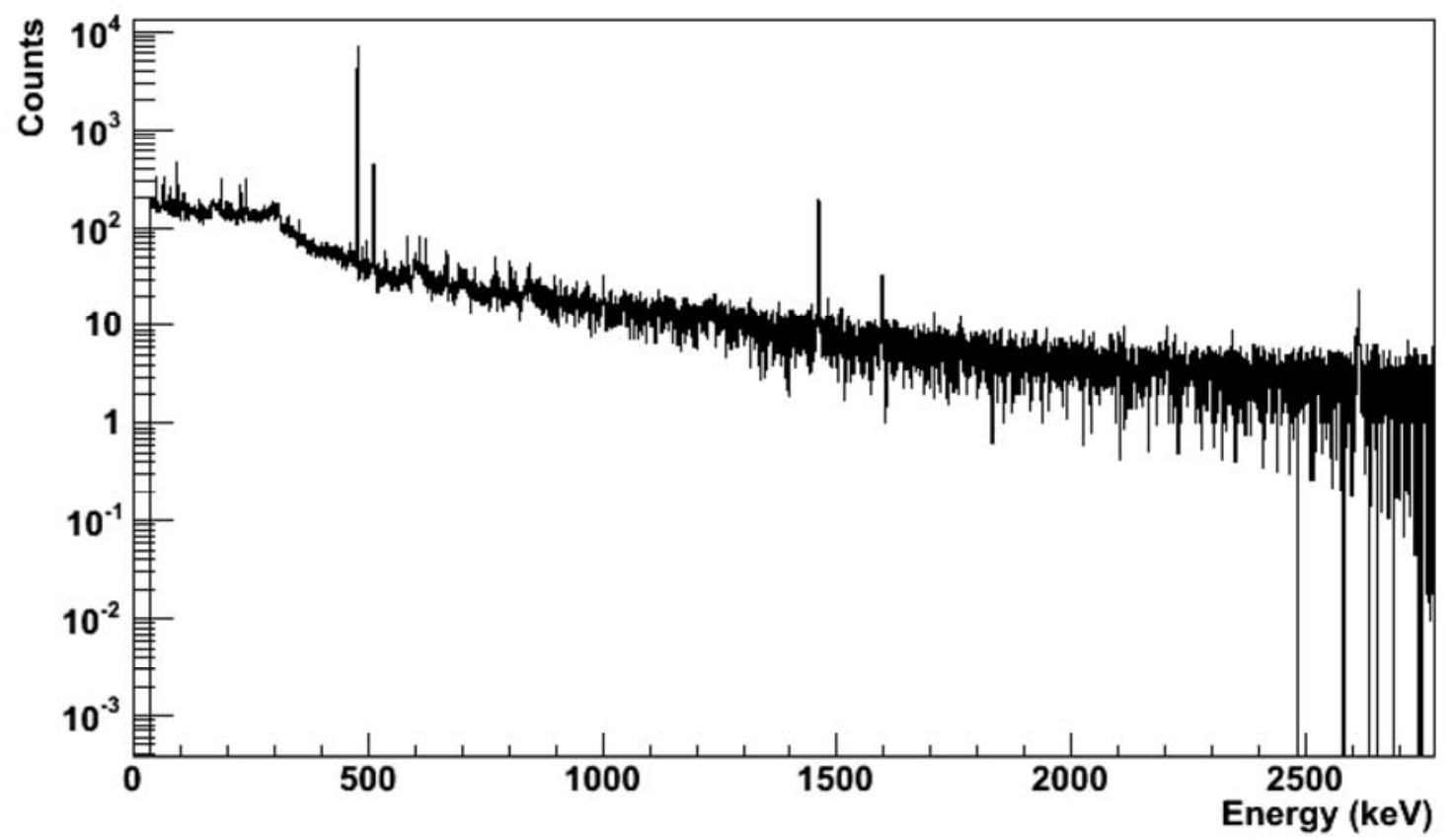

Figure 4: Sample 5 represents the most complex spectrum for analysis. In this case the isotopes are a mixture of fission products $\left({ }^{103} \mathrm{Ru},{ }^{106} \mathrm{Ru},{ }^{132} \mathrm{Te},{ }^{132} \mathrm{I},{ }^{137} \mathrm{Cs},{ }^{140} \mathrm{Ba},{ }^{140} \mathrm{La}\right)$ and the ${ }^{239} \mathrm{~Np}$ activation product. 


\subsection{Criteria}

Evaluation of the DCAL data is complicated by the fact that the 'book answer' is unknown. However, PNNL does have a substantial gamma spectroscopy team responsible, among other things, for the operation of Radionuclide Laboratory 16 (RL-16). The certification of RL-16 as a recognized station of the CTBTO's verification regime includes a technically intensive process to verify the accuracy of spectroscopy techniques. Additionally, the leader of this team is PNNL laboratory fellow Dr. Larry Greenwood, a world-renowned expert in gamma spectroscopy.

For this report, the evaluation of the DCAL data assumes that the results produced by Dr. Greenwood's team are correct within the errors. Still, it is worth noting that the samples counted on CASCADES typically differed by an order of magnitude in activity from those counted by the RL-16 detectors. Therefore, the results are given in terms of atoms per gram of the original solution that was separately diluted for each sample.

The PTE challenges differ fundamentally from the DCAL tests in that the spectra originate from Monte Carlo simulation. The CTBTO explored the accuracy of their simulation approach in the PTE2003 event and found the results accurate for most isotopes - so for this reason the activity injected into the spectrum in Monte Carlo simulation is treated as the "book answer." In the PTE2003 technical report, this injected value is compared with each laboratory result in terms of two criteria. The first evaluation involves the use of a u-test, which consists of measuring the separation between the injected value and the analyzed result in terms of the number of sigma quoted in the laboratory result. The PTE considered u-test values less than 1.64 to indicate agreement between the PTE injected value and the reported results and within the reported uncertainty. Secondly, CTBTO tested whether the reported value of the PTE was within $10 \%$ of the injected value. Since a high reported uncertainty could indicate agreement under the u-test even for reported values far from the correct answer, this second test rewards an analysis for accuracy regardless of uncertainty. 
PNNL-22992

\subsection{Results}

This section provides tabularized results for each data set.

Table 1: DCAL30

\begin{tabular}{|c|c|c|}
\hline & Greenwood et al. using Genie PC & CASCADES using Melusine \\
\hline Isotope or ratio & Atoms/g with $1 \sigma$ uncertainty & Atoms/g with 10 uncertainty \\
\hline \multicolumn{3}{|c|}{ Au Foil } \\
\hline${ }^{194} \mathrm{Au} *$ & $1.48 \mathrm{E}+09 \pm 3.3 \%$ & $1.46 \mathrm{E}+09 \pm 2.1 \%$ \\
\hline${ }^{195} \mathrm{Au} *$ & $7.51+09 \pm 4.5 \%$ & $7.71 \mathrm{E}+09 \pm 2.5 \%$ \\
\hline${ }^{196} \mathrm{Au}$ & $1.71 \mathrm{E}+10 \pm 2.6 \%$ & $1.66 \mathrm{E}+09 \pm 2.1 \%$ \\
\hline${ }^{198} \mathrm{Au}$ & $1.13 E+09 \pm 3.3 \%$ & $1.09 \mathrm{E}+09 \pm 2.0 \%$ \\
\hline \multirow[t]{2}{*}{${ }^{199} \mathrm{Au}$} & $<9.78 \mathrm{E}+06$ Atoms / g & $<3.31 \mathrm{E}+06$ Atoms / g \\
\hline & $<$ 9.70E+06 Atoms in sample 325.1 & $<1.41 \mathrm{E}+05$ Atoms in sample 3425 \\
\hline${ }^{195} \mathrm{Au} /{ }^{196} \mathrm{Au}$ & $0.197 \pm 5.2 \%$ & $0.201 \pm 3.3 \%$ \\
\hline${ }^{194} \mathrm{Au} /{ }^{195} \mathrm{Au}$ & $0.439 \pm 5.2 \%$ & $0.454 \pm 3.2 \%$ \\
\hline${ }^{198} \mathrm{Au} /{ }^{196} \mathrm{Au}$ & $0.066 \pm 4.3 \%$ & $0.065 \pm 2.8 \%$ \\
\hline${ }^{199} \mathrm{Au} /{ }^{198} \mathrm{Au}$ & NA & NA \\
\hline
\end{tabular}

Ti Foil

\begin{tabular}{|c|c|c|}
\hline${ }^{44 m} \mathrm{Sc}$ & $2.54 \mathrm{E}+07 \pm 2.1 \%$ & $2.49 \mathrm{E}+07 \pm 2.1 \%$ \\
\hline${ }^{46} \mathrm{Sc}$ & $1.96 \mathrm{E}+09 \pm 1.7 \%$ & $1.94 \mathrm{E}+09 \pm 2.0 \%$ \\
\hline${ }^{47} \mathrm{Sc}$ & $3.67 \mathrm{E}+09 \pm 2.9 \%$ & $3.74 \mathrm{E}+09 \pm 2.0 \%$ \\
\hline${ }^{48} \mathrm{Sc}$ & $1.76 \mathrm{E}+09 \pm 2.9 \%$ & $1.82 \mathrm{E}+09 \pm 2.0 \%$ \\
\hline${ }^{47} \mathrm{Ca}$ & $3.56 \mathrm{E}+07 \pm 2.2 \%$ & $3.51 \mathrm{E}+07 \pm 2.0 \%$ \\
\hline${ }^{47} \mathrm{Sc} /{ }^{46} \mathrm{Sc}$ & $1.87 \mathrm{E}+00 \pm 3.3 \%$ & $1.92 \mathrm{E}+00 \pm 2.8 \%$ \\
\hline${ }^{48} \mathrm{Sc} /{ }^{47} \mathrm{Sc}$ & $4.81 \mathrm{E}-01 \pm 4.0 \%$ & $4.85 \mathrm{E}-01 \pm 2.8 \%$ \\
\hline
\end{tabular}


PNNL-22992

\begin{tabular}{|c|c|c|}
\hline & Greenwood et al. using Genie PC & CASCADES using Melusine \\
\hline Isotope or ratio & Atoms/g with $1 \sigma$ uncertainty & Atoms/g with $1 \sigma$ uncertainty \\
\hline${ }^{44 \mathrm{~m}} \mathrm{Sc} /{ }^{46} \mathrm{Sc}$ & $1.29 \mathrm{E}-01 \pm 2.7 \%$ & $1.28 \mathrm{E}-02 \pm 2.9 \%$ \\
\hline \multicolumn{3}{|c|}{ Ni Foil } \\
\hline${ }^{56} \mathrm{Ni}^{*}$ & $9.86 \mathrm{E}+06 \pm 3.9 \%$ & $1.12 \mathrm{E}+07 \pm 6.2 \%$ \\
\hline${ }^{57} \mathrm{Ni}$ & $1.63 E+09 \pm 2.7 \%$ & $1.79 E+09 \pm 2.0 \%$ \\
\hline${ }^{55} \mathrm{Co} *$ & $5.58 \mathrm{E}+06 \pm 18.2 \%$ & $1.33 \mathrm{E}+08 \pm 8.1 \%$ \\
\hline${ }^{56} \mathrm{Co}$ & $8.06 E+08 \pm 1.5 \%$ & $8.65 E+08 \pm 2.0 \%$ \\
\hline${ }^{57} \mathrm{Co}$ & $2.05 E+10 \pm 3.3 \%$ & $2.20+\mathrm{E} 10 \pm 2.0 \%$ \\
\hline${ }^{58} \mathrm{Co}$ & $1.79 \mathrm{E}+10 \pm 2.1 \%$ & $1.98+\mathrm{E} 10 \pm 2.0 \%$ \\
\hline${ }^{60} \mathrm{Co}$ & $4.16 E+06 \pm 4.8 \%$ & $4.49 E+06 \pm 3.7 \%$ \\
\hline${ }^{59} \mathrm{Fe}$ & $4.17 \mathrm{E}+07 \pm 4.0 \%$ & $4.81 E+07 \pm 3.8 \%$ \\
\hline${ }^{54} \mathrm{Mn}^{*}$ & $6.61 E+08 \pm 2.5 \%$ & $7.31 E+08 \pm 2.5 \%$ \\
\hline${ }^{56} \mathrm{Mn}$ & $\begin{array}{c}<1.18 \mathrm{E}+15 \text { Atoms / g } \\
<1.31 \mathrm{E}+15 \text { Atoms } \\
\text { in sample } 325.1\end{array}$ & $\begin{array}{c}<1.88 \mathrm{E}+11 \text { Atoms / g } \\
<1.83 \mathrm{E}+10 \text { Atoms } \\
\text { in sample } 3425\end{array}$ \\
\hline${ }^{56} \mathrm{Ni} /{ }^{57} \mathrm{Ni}$ & $6.06 \mathrm{E}-03 \pm 4.7 \%$ & $6.279 \mathrm{E}-03 \pm 6.5 \%$ \\
\hline${ }^{55} \mathrm{Co} /{ }^{56} \mathrm{Co}$ & $6.93 \mathrm{E}-03 \pm 18.2 \%$ & $1.541 \mathrm{E}-01 \pm 8.3 \%$ \\
\hline${ }^{56} \mathrm{Co} /{ }^{57} \mathrm{Co}$ & $3.92 \mathrm{E}-02 \pm 3.6 \%$ & $3.93 \mathrm{E}-02 \pm 2.9 \%$ \\
\hline${ }^{57} \mathrm{Co} /{ }^{58} \mathrm{Co}$ & $1.15 \mathrm{E}+00 \pm 3.9 \%$ & $1.11 E+00 \pm 2.8 \%$ \\
\hline${ }^{58} \mathrm{Co} /{ }^{60} \mathrm{Co}$ & $1.08 \mathrm{E}+014.30 \mathrm{E}+03 \pm 5.3 \%$ & $4.41 \mathrm{E}+03 \pm 4.2 \%$ \\
\hline${ }^{56} \mathrm{Mn} /{ }^{54} \mathrm{Mn}$ & NA & NA \\
\hline
\end{tabular}

Fe Foil

${ }^{56} \mathrm{Co}$ * 


\begin{tabular}{|c|c|c|}
\hline & Greenwood et al. using Genie PC & CASCADES using Melusine \\
\hline Isotope or ratio & Atoms/g with $1 \sigma$ uncertainty & Atoms/g with $1 \sigma$ uncertainty \\
\hline${ }^{52} \mathrm{Fe}$ & $\begin{array}{c}<3.99 \mathrm{E}+06 \text { Atoms / g } \\
<4.44 \mathrm{E}+6 \text { Atoms } \\
\text { in sample } 325.1\end{array}$ & $\begin{array}{c}<8.85 \mathrm{E}+06 \text { Atoms / g } \\
<9.85 \mathrm{E}+06 \text { Atoms } \\
\text { in sample } 3425\end{array}$ \\
\hline${ }^{52} \mathrm{Mn}$ & $5.57 \mathrm{E}+07 \pm 2.3 \%$ & $5.47 \mathrm{E}+07 \pm 2.0 \%$ \\
\hline${ }^{54} \mathrm{Mn}$ & $3.97 E+09 \pm 1.1 \%$ & $4.03 E+09 \pm 2.0 \%$ \\
\hline${ }^{56} \mathrm{Mn}$ & $\begin{array}{c}<2.80 \mathrm{E}+12 \text { Atoms / g } \\
<3.12 \mathrm{E}+12 \text { Atoms } \\
\text { in sample } 325.1\end{array}$ & $\begin{array}{c}<1.79 \mathrm{E}+09 \text { Atoms / g } \\
<1.99 \mathrm{E}+09 \text { Atoms } \\
\text { in sample } 3425\end{array}$ \\
\hline${ }^{51} \mathrm{Cr}$ & $4.81 E+08 \pm 2.1 \%$ & $4.77 \mathrm{E}+08 \pm 2.1 \%$ \\
\hline${ }^{48} \mathrm{SC}^{*}$ & & $1.83 E+05 \pm 9.2 \%$ \\
\hline${ }^{52} \mathrm{Mn} /{ }^{54} \mathrm{Mn}$ & $1.40 \mathrm{E}-02 \pm 2.5 \%$ & $1.36 \mathrm{E}-02 \pm 2.8 \%$ \\
\hline${ }^{56} \mathrm{Mn} /{ }^{54} \mathrm{Mn}$ & NA & NA \\
\hline
\end{tabular}

* One of the isotopes for which Melusine's results disagreed across measurements greater than the uncertainty indicated by any one measurement

For the gold, iron, and titanium foils, Melusine analysis results for samples measured on the CASCADES germanium array agreed with results from PNNL's standard HPGe systems that were analyzed with Genie PC. On the nickel foil, Melusine/CASCADES results were consistently high by about $10 \%$. This discrepancy was seen across multiple isotopes and energies and is interpreted to indicate an error outside the analysis routines of Melusine (e.g., pipetting error, sample data transposition error, or something similar that would affect all isotopes).

For a small number of isotopes, Melusine's results showed disagreements across measurements greater than the uncertainty indicated by any one measurement (indicated by an asterisk next to the isotope in the table above). This can result from a number of issues, including parent-daughter relationships that keep the isotope from achieving equilibrium during one or more count, difficulties with incorrect nuclear data, and others.

\subsection{PTE2003}

To date, the emphasis has been on the comparison of results from the PTE2005 challenge as described in Section 2.3 above. Therefore, the comparative analysis of Melusine's results to those from PTE2003 is incomplete at this time. 
PNNL-22992

\subsection{PTE2005}

Table 2: Summary Table Describing Injected and Measured Activities for Each Sample (all values in Becquerels)

\begin{tabular}{|l|l|l|l|l|}
\hline & \multicolumn{3}{|c|}{ Injected and Measured Activities in Bq } \\
\hline Nuclide & VGSL & PTS1 & PTS2 & Melusine \\
\hline
\end{tabular}

Sample 1

\begin{tabular}{|l|l|l|l|l|}
\hline${ }^{7} \mathrm{Be}$ & 57.928 & $57.52 \pm 0.8 \%$ & $58.03 \pm 1.8 \%$ & $57.91 \pm 0.8 \%$ \\
\hline${ }^{210} \mathrm{~Pb}$ & 10.073 & $10.01 \pm 14.5 \%$ & $10.33 \pm 35.1 \%$ & $16.5 \pm 17.3 \%$ \\
\hline
\end{tabular}

Sample 2

\begin{tabular}{|l|l|l|l|l|}
\hline${ }^{7} \mathrm{Be}$ & 76.271 & $75.24 \pm 0.7 \%$ & $75.97 \pm 1.7 \%$ & $75.72 \pm 0.7 \%$ \\
\hline${ }^{210} \mathrm{~Pb}$ & 5.089 & $4.85 \pm 34.8 \%$ & $5.453 \pm 38.8 \%$ & $9.10 \pm 18.5 \%$ \\
\hline
\end{tabular}

\section{Sample 3}

\begin{tabular}{|c|c|c|c|c|}
\hline${ }^{7} \mathrm{Be}$ & 47.397 & $46.90 \pm 0.8 \%$ & $47.18 \pm 1.8 \%$ & $47.31 \pm 0.9 \%$ \\
\hline${ }^{132} \mathrm{Te}$ & 0.013 & $0.016 \pm 31.5 \%$ & $0.016 \pm 11.9 \%$ & $0.019 \pm 43.9 \%$ \\
\hline${ }^{132} \mathrm{~F}$ & no detection & no detection & no detection \\
\hline${ }^{140} \mathrm{Ba}$ & 0.014 & no detection & no detection & peak $<\mathrm{L}_{\mathrm{c}}$ \\
\hline${ }^{140} \mathrm{La}$ & 0.020 & $0.037 \pm 20.6 \%$ & $0.033 \pm 12.8 \%$ & $0.034 \pm 27.4 \%$ \\
\hline $210 \mathrm{~Pb}$ & 8.958 & $10.95 \pm 11.3 \%$ & $10.04 \pm 35.2 \%$ & $9.50 \pm 25.3 \%$ \\
\hline
\end{tabular}

Sample 4

\begin{tabular}{|c|c|c|c|c|}
\hline${ }^{7} \mathrm{Be}$ & 87.266 & $84.57 \pm 0.7 \%$ & $86.90 \pm 1.7 \%$ & $86.99 \pm 0.6 \%$ \\
\hline${ }^{126} \mathrm{Sb}$ & 0.131 & $0.079 \pm 9.2 \%$ & $0.080 \pm 3.9 \%$ & $0.075 \pm 8.4 \%$ \\
\hline${ }^{131} \mathrm{I}$ & 0.015 & $0.017 \pm 32.8 \%$ & $0.019 \pm 10.6 \%$ & $0.024 \pm 45 \%$ \\
\hline${ }^{137} \mathrm{Cs}$ & 0.017 & $0.017 \pm 31.3 \%$ & $0.018 \pm 12.6 \%$ & $0.019 \pm 50.8 \%$ \\
\hline${ }^{210} \mathrm{~Pb}$ & 5.134 & $10.19 \pm 12.5 \%$ & $10.71 \pm 35.0 \%$ & $6.80 \pm 38.0 \%$ \\
\hline
\end{tabular}


PNNL-22992

\begin{tabular}{|c|c|c|c|c|}
\hline & \multicolumn{4}{|c|}{ Injected and Measured Activities in Bq } \\
\hline Nuclide & VGSL & PTS1 & PTS2 & Melusine \\
\hline \multicolumn{5}{|c|}{ Sample 5} \\
\hline${ }^{7} \mathrm{Be}$ & 64.830 & $65.04 \pm 0.8 \%$ & $64.95 \pm 1.7 \%$ & $64.73 \pm 0.8 \%$ \\
\hline${ }^{103} \mathrm{Ru}$ & 0.045 & $0.049 \pm 10.8 \%$ & $0.043 \pm 7.3 \%$ & $0.042 \pm 18.1 \%$ \\
\hline${ }^{106} \mathrm{Ru}$ & 0.738 & $0.67 \pm 9.7 \%$ & $0.61 \pm 6.9 \%$ & $0.56 \pm 18.1 \%$ \\
\hline${ }^{132} \mathrm{Te}$ & 0.066 & $0.075 \pm 9.2 \%$ & $0.071 \pm 9.6 \%$ & $0.076 \pm 13.9 \%$ \\
\hline${ }^{132}{ }_{1}$ & 0.068 & $0.051 \pm 15.9 \%$ & $0.047 \pm 7.9 \%$ & $0.059 \pm 12.9 \%$ \\
\hline${ }^{137}$ Cs & 0.024 & $0.024 \pm 24.6 \%$ & $0.025 \pm 10.7 \%$ & $0.026 \pm 44.9 \%$ \\
\hline${ }^{140} \mathrm{Ba}$ & 0.081 & $0.083 \pm 21.8 \%$ & $0.081 \pm 19.6 \%$ & $0.092 \pm 24.1 \%$ \\
\hline${ }^{140} \mathrm{La}$ & 0.093 & $0.101 \pm 9.8 \%$ & $0.099 \pm 7.6 \%$ & $0.093 \pm 11.3 \%$ \\
\hline${ }^{210} \mathrm{~Pb}$ & 6.880 & $11.02 \pm 12.4 \%$ & $10.92 \pm 35.2 \%$ & $6.62 \pm 32.3 \%$ \\
\hline${ }^{239} \mathrm{~Np}$ & 0.137 & $0.132 \pm 14.7 \%$ & $0.137 \pm 6.1 \%$ & $0.143 \pm 18.3 \%$ \\
\hline
\end{tabular}

Beryllium-7: The 477.6-keV peak from ${ }^{7} \mathrm{Be}$ is present in all five of the PTE2005 test spectra. This line did not experience interference problems, and does not suffer from summing effects. Most results from all three analyses were accurate, although there were cases for which results failed the u-test, perhaps due to overly small uncertainties being reported.

\section{$\underline{\text { Sample } 1}$}

PTE1 in agreement with VGSL: YES

PTE2 in agreement with VGSL: YES

Melusine in agreement with VGSL: YES

\section{$\underline{\text { Sample } 2}$}

PTE1 in agreement with VGSL: NO

PTE2 in agreement with VGSL: YES

Melusine in agreement with VGSL: YES

\section{$\underline{\text { Sample } 3}$}

PTE1 in agreement with VGSL: YES

PTE2 in agreement with VGSL: YES

Melusine in agreement with VGSL: YES 
PNNL-22992

\section{Sample 4}

PTE1 in agreement with VGSL: NO

PTE2 in agreement with VGSL: YES

Melusine in agreement with VGSL: YES

\section{Sample 5}

PTE1 in agreement with VGSL: YES

PTE2 in agreement with VGSL: YES

Melusine in agreement with VGSL: YES

Ruthenium-103: A 497.1-keV line dominates the detection and measurement of activity. There is a nearby interference at $473.9 \mathrm{keV}$, but it seems to have little effect.

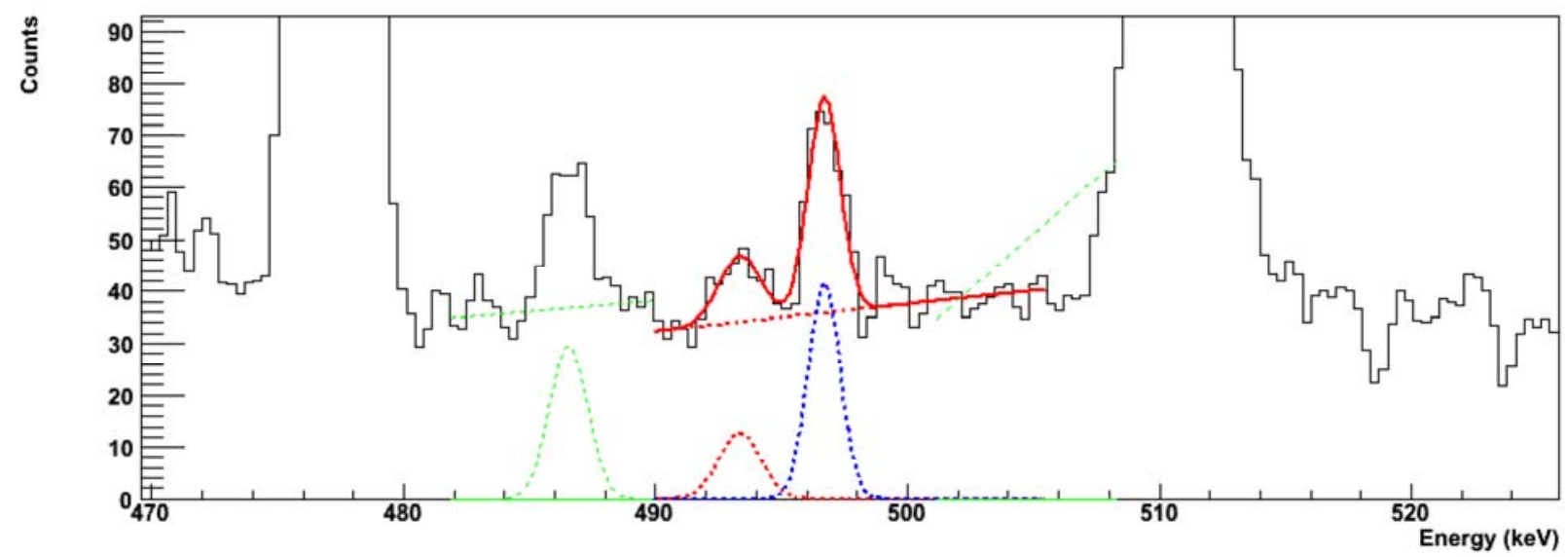

Figure 5: Fitting the 497.1-keV gamma (blue line) in Sample 5

\section{Sample 5}

PTE1 in agreement with VGSL: YES

PTE2 in agreement with VGSL: YES

Melusine in agreement with VGSL: YES

Ruthenium-106: This isotope was measured based on the gamma emissions from its short-lived daughter, ${ }^{106} \mathrm{Rh}\left(\mathrm{t}_{1 / 2}=29.8\right.$ seconds), which was present in the Sample 5 spectrum. Ruthenium-106 was identified and quantified in all three analyses. All three reported the activity value to be low compared to the VGSL activity. The IMS analyses were $9 \%$ and $17.5 \%$ low, while Melusine was $24 \%$ low. Melusine reported a higher uncertainty in the result, yielding a lower $\mathrm{u} 1$ value than the PTE2 result. The fit used by Melusine was affected by neighboring features in the spectrum, and appears to have established the continuum background too high, reducing the peak area and calculated activity (see Figure 6 below). Melusine also used an intensity of $10.2 \%$, while several references list the $621.9-\mathrm{keV}$ line of ${ }^{106} \mathrm{Rh}$ at $9.8 \%$. If this represents a discrepancy between the VGSL and Melusine nuclear data libraries, it would account for $\sim 2.8 \%$ of the difference. 
PNNL-22992

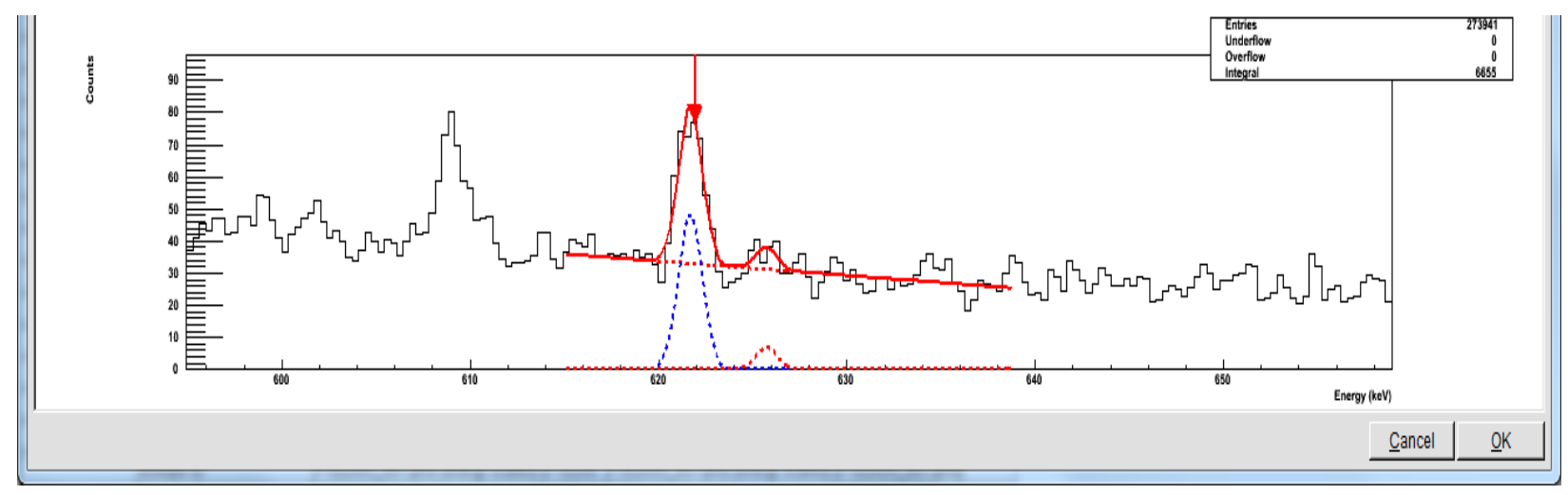

Figure 6: Melusine's fit to the $621.9 \mathrm{keV}$ line in Sample 5

\section{$\underline{\text { Sample } 5}$}

PTE1 in agreement with VGSL: YES

PTE2 in agreement with VGSL: NO

Melusine in agreement with VGSL: NO

Antimony-126: In the PTE2003 exercise, this isotope was only detected by 6 of the 16 participating labs despite the 7 detectable peaks in the sample data. For the 2005 exercise, only Sample 4 had ${ }^{126} \mathrm{Sb}$, and 5 of the detectable peaks were statistically significant (Khrustalev 2013). However, the decay structure causes substantial summing effects, which complicates the activity calculation. Although PTE1, PTE2 and Melusine all detected the isotope, none of the results are in agreement with the VGSL injected value. All three analyses are in agreement with one another.

\section{Sample 4}

PTE1 in agreement with VGSL: NO

PTE2 in agreement with VGSL: NO

Melusine in agreement with VGSL: NO

Iodine-131: Iodine-131 activity values were reported for all analyses of Sample 4. PTE1 and Melusine passed the u-test, while PTE2 did not. This is likely due to an overly optimistic uncertainty estimate for PTE2, which reported a value much closer to the VGSL activity (26\% high) than did Melusine $(60 \%$ high). The difference was that Melusine estimated a 45\% uncertainty, while PTE2 estimated a 10.6\% uncertainty.

\section{Sample 4}

PTE1 in agreement with VGSL: YES

PTE2 in agreement with VGSL: NO

Melusine in agreement with VGSL: YES

Tellurium-132: This isotope tended to have a substantial positive bias for PTE and Melusine analysis. The primary $228.1-\mathrm{keV}$ line was the only one strong enough for activity calculation in these spectra. 
PNNL-22992

Sample 3 had a weak activity, and Sample 5 introduced the complication of interference from the 228.2-keV line from ${ }^{239} \mathrm{~Np}$. While all results were in agreement with the VGSL value, PTE2 on Sample 5 was the only result within $10 \%$ of the injected value.

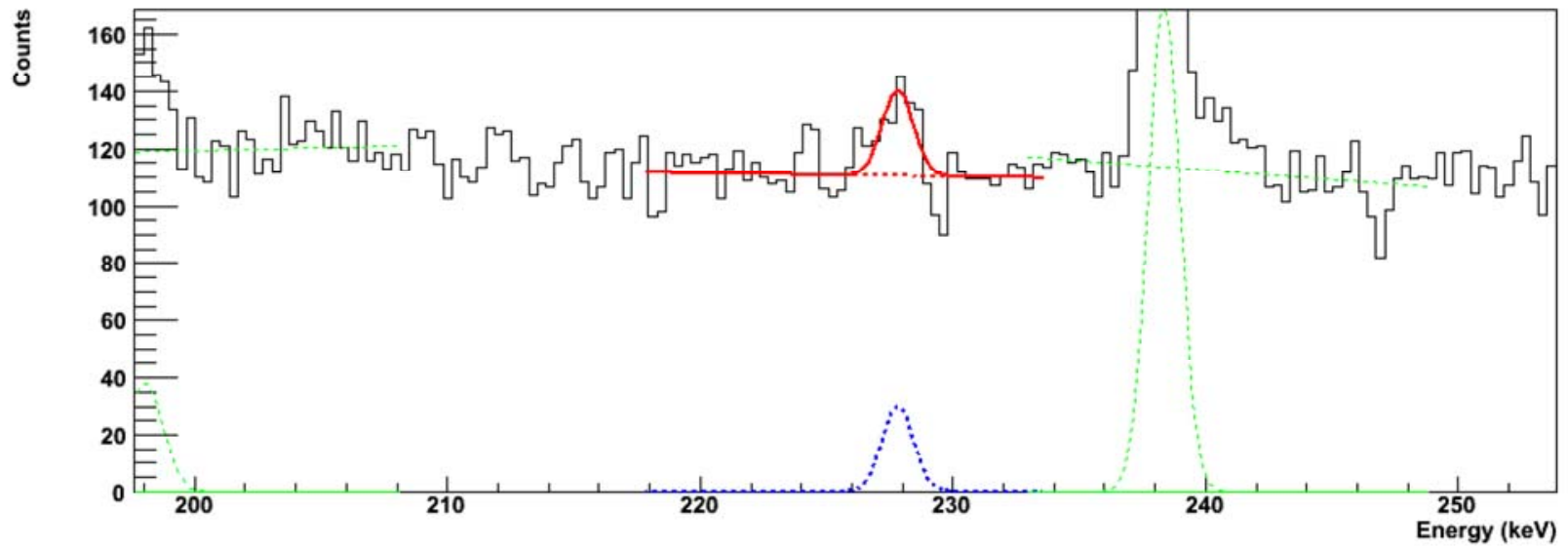

Figure 7: Fitting the weak 228.2-keV peak (blue line) in Sample3

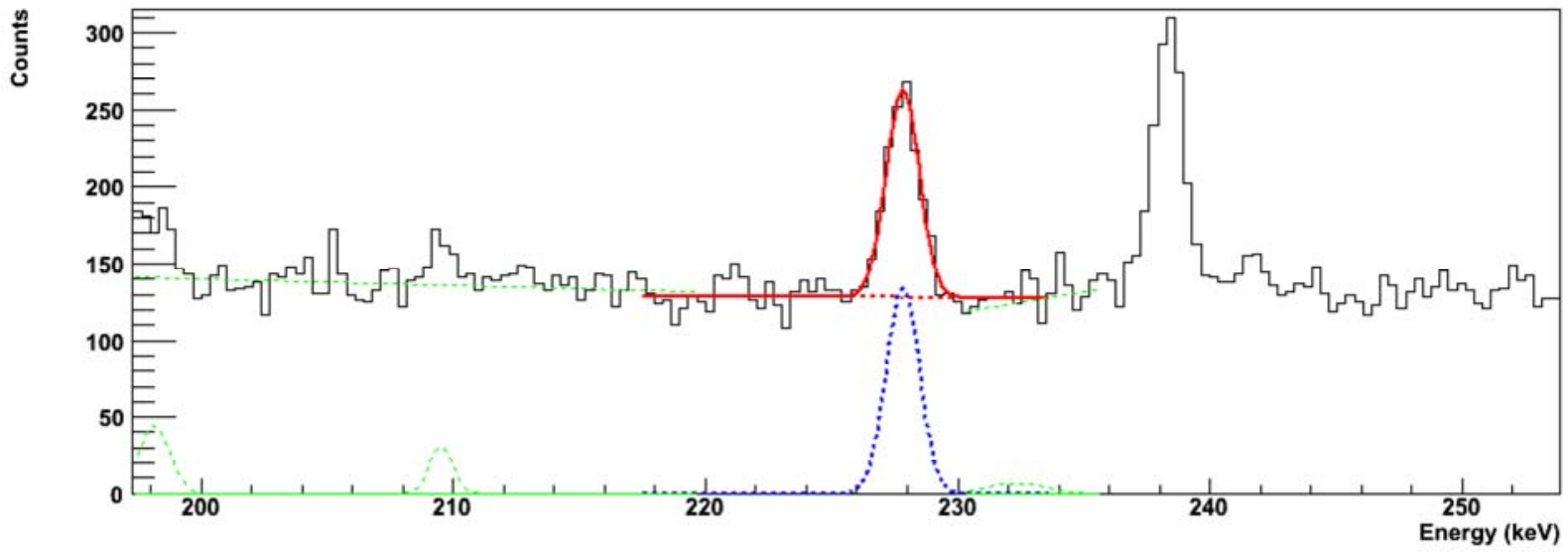

Figure 8: Fitting the stronger peak (blue line) in Sample 5, which includes interference from ${ }^{239} \mathrm{~Np}$

\section{Sample 3}

PTE1 in agreement with VGSL: YES

PTE2 in agreement with VGSL: YES

Melusine in agreement with VGSL: YES

\section{Sample 5}

PTE1 in agreement with VGSL: YES

PTE2 in agreement with VGSL: YES

Melusine in agreement with VGSL: YES 
Iodine-132: The daughter of ${ }^{132} \mathrm{Te},{ }^{132} \mathrm{I}$ has a half-life of 137 minutes and two primary gammas at 667.7 and $772.7 \mathrm{keV}$. Though this isotope was injected into the spectra for Samples 3 and 5, it was not detected by any of the analyses of Sample 3. Tellurium-132 was detected in this sample, so despite the higher Compton continuum at $228 \mathrm{keV}$ (versus, for example, the $667.7-\mathrm{keV}$ line of ${ }^{132} \mathrm{I}$ ), the higher detection efficiency at $228 \mathrm{keV}$ resulted in better sensitivity for ${ }^{132} \mathrm{Te}$ than for ${ }^{132} \mathrm{I}$. None of the analysis results for Sample 5 were within $10 \%$ of the VGSL value.

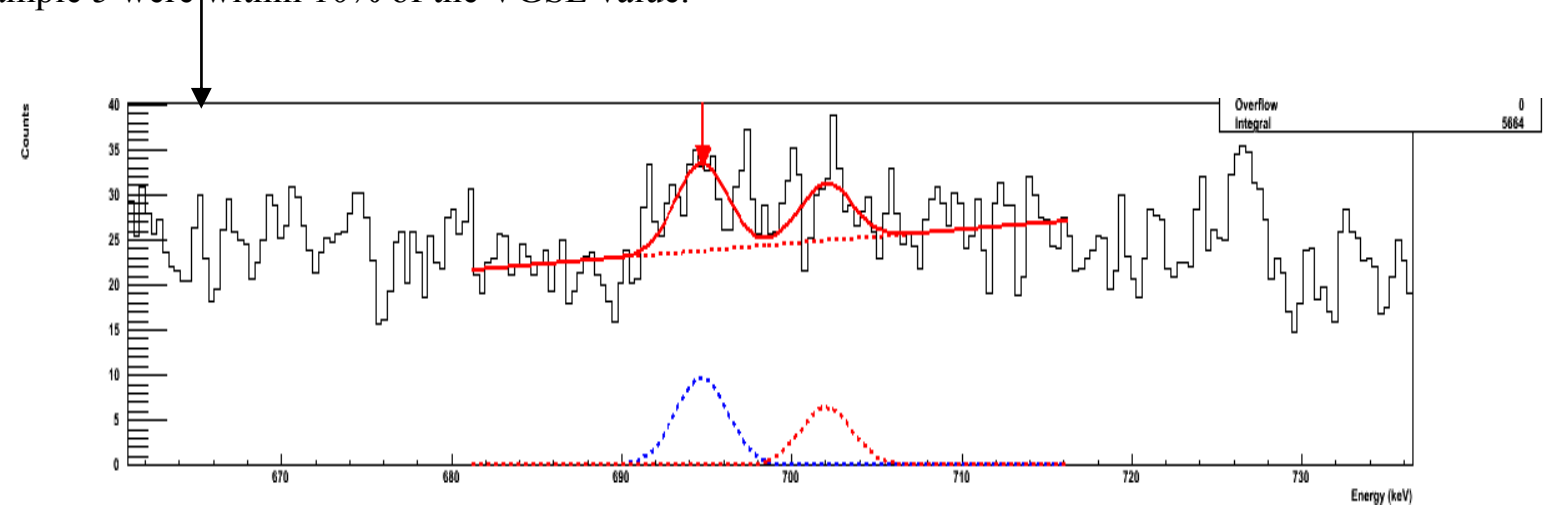

Figure 9: Fitting the $667.7-\mathrm{keV}$ line in Sample 5

\section{Sample 3}

PTE1 in agreement with VGSL: NO - Not Detected

PTE2 in agreement with VGSL: NO - Not Detected

Melusine in agreement with VGSL: NO - Not Detected

\section{Sample 5}

PTE1 in agreement with VGSL: NO

PTE2 in agreement with VGSL: NO

Melusine in agreement with VGSL: YES

Cesium-137: All three analyses agreed with the VGSL injected value. In all cases, the results are within the $10 \%$ of the VGSL value, except for Melusine's Sample 5 result, which differs by $12 \%$.

\section{Sample 4}

PTE1 in agreement with VGSL: YES

PTE2 in agreement with VGSL: YES

Melusine in agreement with VGSL: YES

\section{Sample 5}

PTE1 in agreement with VGSL: YES

PTE2 in agreement with VGSL: YES

Melusine in agreement with VGSL: YES

Barium-140: This isotope was not detected by any of the analyses of Sample 3, although its daughter, ${ }^{140} \mathrm{La}$, was measured. All three analyses agreed with the VGSL injected value for Sample 5. In all cases, 
the results are within the $10 \%$ of the VGSL value except for Melusine's result, which differs by $13.6 \%$ (this is consistent with the VGSL value due to a reported uncertainty of 25\%).

\section{Sample 3}

PTE1 in agreement with VGSL: NO - Not Detected

PTE2 in agreement with VGSL: NO - Not Detected

Melusine in agreement with VGSL: NO - Not Detected

\section{Sample 5}

PTE1 in agreement with VGSL: YES

PTE2 in agreement with VGSL: YES

Melusine in agreement with VGSL: YES

Lanthanum-140: All three analyses reported the value of ${ }^{140}$ La roughly $50 \%$ higher than the VGSL value. This discrepancy appears likely to be associated with the decay correction for ${ }^{140} \mathrm{La}$. The activity in Sample 5 was roughly 4 times higher than in Sample 3, and analysis results were consistent with the VGSL value.

\section{Sample 3}

PTE1 in agreement with VGSL: NO

PTE2 in agreement with VGSL: NO

Melusine in agreement with VGSL: YES

\section{Sample 5}

PTE1 in agreement with VGSL: YES

PTE2 in agreement with VGSL: YES

Melusine in agreement with VGSL: YES

Lead-210: This isotope was problematic through all three analyses. The sole peak, at $46.5 \mathrm{keV}$, is in a region of high noise and also is present in background measurements. The PTE results are superior on the first two samples, but fall into disagreement (or nearly so) with the last three samples. Melusine's results are almost reversed, so that the agreement improves in the higher activity samples. For all PTE and Melusine analysis, only Melusine's results of Samples 3 and 5 are within 10\% of the expected VGSL value. Melusine peak fits appear to be acceptable for all five spectra; the cause of the result being twice the expected result in the first two samples has not been determined. The fact that Melusine determined accurate results for spectra 3-5 indicates that this should not be associated with an error in the nuclear data. 
PNNL-22992

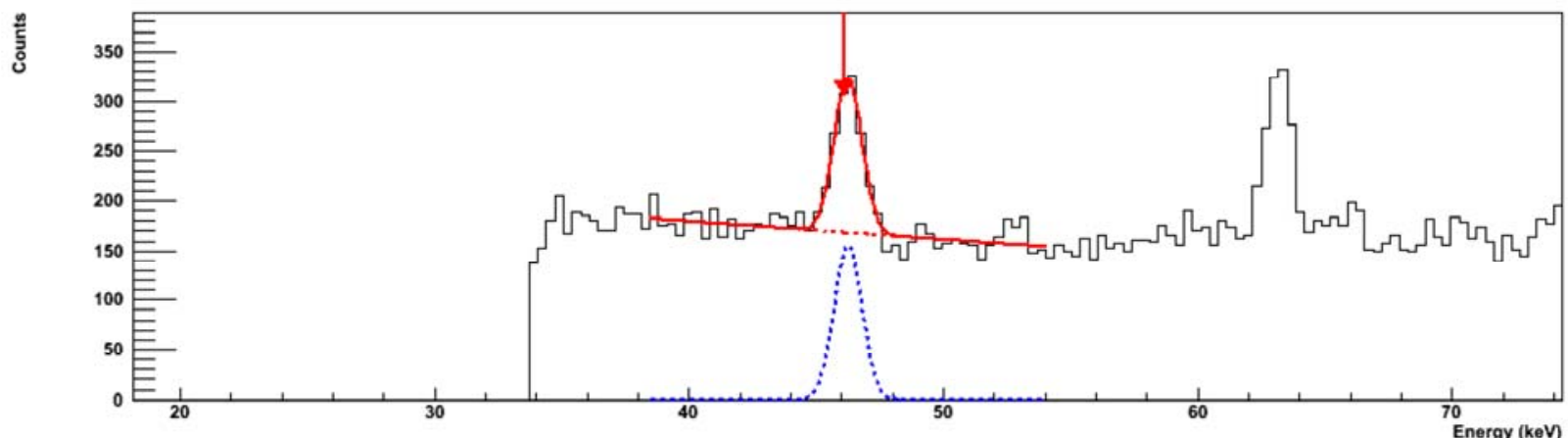

Figure 10: Fitting the $46.5-\mathrm{keV}$ peak for ${ }^{210} \mathrm{~Pb}$ in Sample 5

\section{Sample 1}

PTE1 in agreement with VGSL: YES

PTE2 in agreement with VGSL: YES

Melusine in agreement with VGSL: NO

\section{Sample 2}

PTE1 in agreement with VGSL: YES

PTE2 in agreement with VGSL: YES

Melusine in agreement with VGSL: NO

\section{Sample 3}

PTE1 in agreement with VGSL: NO

PTE2 in agreement with VGSL: YES

Melusine in agreement with VGSL: YES

\section{Sample 4}

PTE1 in agreement with VGSL: NO

PTE2 in agreement with VGSL: YES

Melusine in agreement with VGSL: YES

\section{Sample 5}

PTE1 in agreement with VGSL: NO

PTE2 in agreement with VGSL: YES

Melusine in agreement with VGSL: YES

Neptunium-239: Present only in Sample 5, this isotope causes interference with the measurement of

${ }^{132}$ Te. The PTE 2003 Technical report (op. cit.) stated:

The nuclide has its main line at $106.1 \mathrm{keV}$, which in this case is also its best line. This is a difficult area in the spectrum due to many peaks close to each other and thus the analysis result depends heavily on deconvolution of multiplets and baseline fitting (p. 21). 
Despite these challenges, all three analyses are in agreement with the VGSL value and are all within 10\% of the injected value.

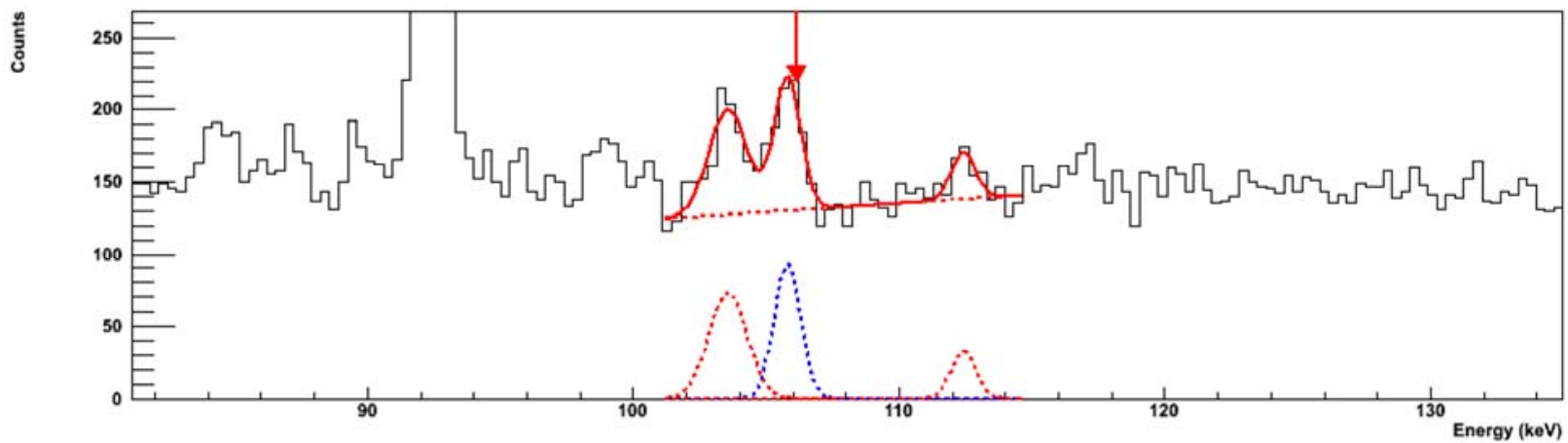

Figure 11: Fitting ${ }^{239} \mathrm{~Np}$ 's $106.1-\mathrm{keV}$ gamma (blue line) in Sample 5

\section{Sample 5}

PTE1 in agreement with VGSL: YES

PTE2 in agreement with VGSL: YES

Melusine in agreement with VGSL: YES 


\subsection{Conclusions}

PNNL has used two data sets to validate the accuracy of results produced by the gamma spectroscopy tool Melusine. The results indicate the Melusine software can successfully conduct analyses, including accurate energy and efficiency calibrations by the measurement of standard sources, sample peak widths to provide a resolution calibration, detecting peaks in a spectrum containing unknown isotopes, properly fitting peak areas, accurately identifying isotopes, calculating activities, and properly propagating statistical errors to calculate uncertainty. These data sets included challenging cases in which the analyst needed to address interferences, summing effects, weak activities, and occasional background subtraction. Melusine produced results that were often comparable and on occasion more accurate than other analysis tools.

For the Davis Calibration, the Melusine results are in agreement with 18 of 20 reported values (excluding the nickel foil, likely due to a material defect during production) as defined by the u-test criteria used by CTBTO's PTE exercises. This is especially significant as uncertainties for this calibration were typically less than 5\%, so the u-test was functionally strict. The Melusine data set had the additional challenge of being the result of a 13-crystal CASCADES array operating simultaneously, which required excellent energy, efficiency, and resolution calibrations.

In the case of the PTE2005 exercise, the Melusine results were in agreement with VGSL injected values in 19 of the 22 cases as defined by the u-test. The two analyses conducted at CTBTO produced agreement in 15 cases and 18 cases, respectively. This suggests that the Melusine software is well suited to processing the spectroscopic data produced by radionuclide stations such as those included in the IMS.

Despite these results, the Melusine software requires further development. Among other topics, effort is needed to simplify the analysis process, improve stability, and provide user documentation. Significant analysis tasks, such as those to address summing effects, also require additional vetting. In spite of these indications of Melusine's early developmental stage, the results reported herein indicate that the calculations presently implemented and used for these analyses are sound and can be used to analyze spectra from the CTBTO's radionuclide stations reliably. 
PNNL-22992

\subsection{References}

CTBTO. 2004. Proficiency Test for Radionuclide Laboratories Supporting the Network of IMS

Radionuclide Stations. Report No. CTBT/PTS/TR/2004-2, Comprehensive Nuclear-Test-Ban Treaty Organization, Vienna, Austria.

Friese, JI, LR Greenwood, M Keillor, LA Metz, KL Noyes, and SG McKinley. 2013. Davis Calibration \#30 - Results from Pacific Northwest National Laboratory. Report No. PNNL-X-900-1587, Pacific Northwest National Laboratory, Richland, WA.

Khrustalev, K. 2013. Discussion between D Haas (Research Scientist (PNNL)) from a CTBTO Surrogate On-Site Inspector training course, "Results from the 2003 and 2005 CTBTO Performance Test Evaluations." March 13, Guntramsdorf, Austria. Copy of materials stored in the CASCADES share drive at PNNL. 
PNNL-22992

\section{Distribution}

No. of

\section{$\underline{\text { Copies }}$}

\# Name

Organization

Address

City, State and ZIP Code

\# Organization

Address

City, State and ZIP Code

Name

Name

Name

Name

Name (\#)

\# Name

Organization

Address

City, State and ZIP Code

No. of

\section{$\underline{\text { Copies }}$}




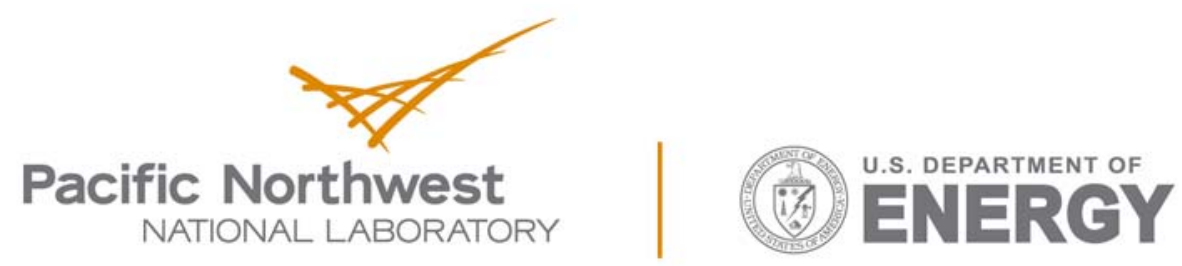

Proudly Operated by Battelle Since 1965

902 Battelle Boulevard

P.O. Box 999

Richland, WA 99352

1-888-375-PNNL (7665)

www.pnnl.gov 